\title{
Pensando a história fora da nação: \\ a historiografia da América Latina e o viés transnacional ${ }^{1}$
}

\section{Barbara Weinstein ${ }^{2}$}

\section{Resumo:}

Este ensaio examina a emergência da "virada transnacional" dentro da profissão de historiador a partir dos anos 1990. Defendo que os historiadores da América Latina desempenharam um papel central na mudança para abordagens transnacionais. Ansiosos para contestar as interpretações históricas que tratam da história da América Latina como uma ramificação econômica, iniciativas políticas e culturais norte-americanas, os latino-americanistas têm procurado elaborar perguntas que transcendam as fronteiras nacionais e demonstrem a circulação de mercadorias, ideias e instituições, tais como a formação global da classe média. A virada transnacional permitiu que historiadores da América Latina, com base na academia norte-americana, demonstrassem que os historiadores dos Estados Unidos precisam prestar atenção à produção de conhecimento sobre a América Latina. Diferente da história internacional, que incide sobre a interação entre as nações, a história transnacional enfatiza questões para as quais o país não é a principal arena de interação ou conflito. A história transnacional também tem iluminado os problemas da história comparativa, com sua tendência a comparar dois casos nacionais estáveis separadamente e a ignorar a circulação e a interação. No entanto, a intenção da história transnacional não é apagar a história nacional, mas complicá-la. E os intelectuais que adotam o viés transnacional precisam considerar as desvantagens de uma abordagem histórica que atenue as conexões nos estudos da América Latina, cuja principal referência analítica ainda é o contexto nacional.

Palavras-chave: transnacional, comparação, circulação, contato, classe média.

\begin{abstract}
:
This essay examines the emergence of the "transnational turn" within the historical profession starting in the 1990s. I argue that historians of Latin America played a central role in the shift to transnational approaches; anxious to contest historical
\end{abstract}

\footnotetext{
${ }^{1} \mathrm{O}$ texto passou por uma revisão bibliográfica, realizada por Caio de Souza Gomes, doutorando no Programa de Pós-Graduação em História Social da USP. E-mail: caio121@uol.com.br

${ }^{2}$ New York University. E-mail: bswein99@aol.com
}

Revista Eletrônica da ANPHLAC, n.14, p. 9-36, jan./jun. 2013.

http://revista.anphlac.org.br/index.php/revista 
interpretations that treat Latin American history as a ramification of North American economic, political and cultural initiatives, Latin Americanists have sought to elaborate questions that transcend national boundaries and demonstrate the circulation of commodities, ideas and bodies such as the global formation of the middle class. The transnational turn has allowed historians of Latin America based in the North American academy to demonstrate that historians of the United States need to pay attention to knowledge production about Latin America. Different from international history, which focuses on the interaction between nations, transnational history emphasizes questions for which the nation is not the principal arena of interaction or conflict. Transnational history has also illuminated the problems of comparative history, with its tendency to compare two stable, separate national cases and ignore circulation and interaction. Nevertheless, the intent of transnational history is not to erase national history, but to complicate it, and scholars following the transnational turn need to consider the drawbacks of a historical approach that attenuates connections to scholars in Latin America whose main analytical reference is still the national context.

Keywords: transnational, comparative, circulation, contact, middle class,

A breve mania que irrompeu na disciplina de História nos anos 70 pelos métodos quantitativos acabou rapidamente. Apesar disso, de vez em quando não há nada melhor que uns números para ilustrar uma tendência - nesse caso, uma tendência historiográfica. Pesquisando o programa eletrônico dos três últimos congressos da American Historical Association para a palavra transnational, consegui (no ano 2010) 120 resultados; em 2011, 135; em 2012, 163. Fazendo o mesmo com o programa do último congresso da LASA (em maio deste ano), descobri que somente no primeiro dia do congresso houve 41 mesas ou comunicações com a palavra transnational/transnacional no título. No mesmo dia do congresso, em 2010, entre aproximadamente o mesmo número de mesas, havia apenas DEZ com transnational ou transnacional no título.

Isso quer dizer, primeiro, que a noção de transnacional está circulando amplamente e influenciando as atuais pesquisas nas áreas de história e de estudos latinoamericanos. E que o uso dessa palavra vai aumentando e virando quase um lugarcomum entre os historiadores. Claro que essa onipresença indica que muitos autores já estão usando a palavra transnacional (com pouca precisão) como um substituto para

Revista Eletrônica da ANPHLAC, n.14, p. 13-29, jan./jun. 2013. http://revista.anphlac.org.br/index.php/revista 
"internacional", porque o primeiro está mais na moda. Mas acho que a sua pujança nesses programas não é devido a um uso meramente superficial. Ela indica certas mudanças na disciplina de História, e especialmente na história da América Latina e do Caribe, que considero mais profundas e interessantes.

Partindo desse pressuposto, minha proposta para o resto desta palestra é historicizar a ascensão do viés transnacional na academia norte-americana e sua relação especial com os estudos latino-americanos, elaborar as contribuições que são, do meu ponto de vista, mais significativas na linha da abordagem transnacional e, finalmente, indicar as promessas e perigos - especialmente para a área de América Latina - desse (relativamente) novo rumo de pesquisa.

Para colocar o viés transnacional num contexto intelectual e acadêmico mais amplo, precisamos levar em consideração uma gama de abordagens que surgiram nos anos 80 e 90 e que provocaram uma leve redistribuição e rearranjo das áreas de pesquisa, especificamente na disciplina de História. Nos departamentos de História nos Estados Unidos daquela época, havia uma distribuição de áreas que era mais ou menos o seguinte: entre 40 e $45 \%$ dos professores se especializavam em Estados Unidos (inclusive aqueles que estudavam "relações exteriores"); entre 35 e $40 \%$ se especializavam na história da Europa; e o restante dos professores - tipicamente, $20 \%$ eram das "outras" áreas - América Latina, Ásia, África, Meio Oriente. A maioria dos meus colegas hoje diria que essa composição é uma coisa do passado e que a história dos Estados Unidos e da Europa (especialmente) já perderam sua preeminência num típico departamento de História. Mas alguns anos atrás fiz um pequeno artigo sobre a distribuição de professores por área de especialização, seguindo as tendências de 1975 até 2005, e fiquei muito impressionada quando vi os resultados e percebi que as proporções continuavam quase inalteradas. Nesse período de 30 anos, e de tantas transformações na disciplina, houve um leve aumento na porcentagem de historiadores que se identificaram como Americanists; o número de historiadores da Europa diminuiu ligeiramente (de 39 a 34\%), e as "outras" ou não mudaram ou sofreram um pequeno aumento. Menos na América Latina, que, para minha surpresa, experimentou um pequeno declínio, em números relativos, descendendo de $7,6 \%$ a $6,4 \%$ nessas três décadas.

$\mathrm{Na}$ verdade, a disciplina de História é, no sentido profissional, conservadora; há fortes correntes e interesses, institucionais e culturais, que impedem uma transformação dramática da disciplina. É muito difícil imaginar a transferência de várias vagas de um 
"setor" para outro. O que é mais provável é que haja um processo de mudança que envolve novas áreas que ignoram ou até desrespeitam os limites das áreas convencionais. E é isso que estava e está acontecendo: desde os anos 90, havia uma expansão marcada em áreas denominadas Atlantic World (mundo atlântico), Diáspora Africana, Pacific Rim (litoral do Pacífico) e Borderlands (terras de fronteiras - que não deve ser confundida com História da Fronteira, que tem uma genealogia muito distinta). Estes, sim, têm o potencial de refazer e renovar um departamento de História.

Essas novas áreas de especialização e pesquisa significam um desafio ao estabelecido padrão de concentração na área de História nos Estados Unidos e, até certo ponto, um desafio ao domínio da nação como o sujeito ou a categoria organizadora das narrativas históricas. E todos eles têm influenciado diretamente os historiadores da América Latina e do Caribe (especialmente o Caribe). Mas, nos casos do Mundo Atlântico e da Diáspora Africana, os estudos mais citados não vão além das primeiras décadas do século XIX e, portanto, eles não oferecem uma nova abordagem para aqueles historiadores cujas pesquisas têm como enfoque o período que coincide com o auge da nação.

Então, num momento em que os trabalhos mais inovadores eram cada vez mais marcados por uma abordagem que atravessava fronteiras e refazia o mapa de regiões de pesquisa, a nação continuava sendo a maior referência para quem trabalhava com os últimos dois séculos (mais ou menos) de história. Ao mesmo tempo, havia entre os teóricos do pós-colonialismo e dos estudos subalternos uma preocupação (citando a frase de Prasenjit Duara) em "resgatar a história da nação". A proposta não é a de negar a importância da nação, mas a de questionar a noção teleológica da nação como o descobrimento inevitável da história e da modernidade.

Pequeno parêntese: vale notar que essa ambivalência com relação à nação era menos forte entre os estudiosos da América Latina. Na teoria pós-colonial, surgida principalmente do sul da Ásia, a nação foi simultaneamente a alternativa ao estado colonial e uma forma moderna de origem explicitamente europeia. Portanto, se o futuro era pensado como inseparável da ascensão da nação, a modernidade sempre ia ser pensada como inseparável do "Ocidente", da Europa. No caso da América Latina, cujas nações foram denominadas, no livro canônico de Benedict Anderson (ANDERSON, 2008), "pioneiros criollos", a nação não virou alvo de tal ambivalência.

Entre os historiadores da América Latina - Latin Americanists (falando especificamente da academia norte-americana) - havia, nos anos 90, certas

Revista Eletrônica da ANPHLAC, n.14, p. 13-29, jan./jun. 2013. http://revista.anphlac.org.br/index.php/revista 
preocupações que refletiram as particularidades da área e da situação de quem estuda América Latina, mas está radicado nos Estados Unidos. De um lado, havia muitas críticas, não inteiramente novas, da noção de area studies. Essa crítica vinha de duas direções. Nas ciências sociais (Sociologia, Ciência Política, Economia) havia um viés econométrico e estatístico que privilegiava o método e os resultados que podem ser "generalizados" e que desvalorizava o conjunto de conhecimentos sobre uma região específica. Area studies, com suas ligações a disciplinas menos "científicas", como História, Antropologia, Literatura, não podiam servir como uma boa base para a carreira de um jovem e ambicioso cientista social que procurava descobrir tendências que se prestaram à generalização. Ao mesmo tempo, havia uma linha de crítica, saindo mais da esquerda, que salientava as raízes de area studies na época da Guerra Fria e, portanto, seu suposto compromisso com certo projeto imperialista, desenvolvimentista ou até orientalista.

Portanto, os Latin Americanists se sentiram obrigados ou a defender seu campo de pesquisa, ou a repensar as fronteiras ou limites do próprio objeto das suas pesquisas. Surgiu o conceito de new American studies, que promoveu uma visão hemisférica e rejeitou uma separação supostamente artificial entre América do Norte e América do Sul, uma noção que fazia sentido em um momento no qual a população latina estava chegando à marca de maior minoria nos Estados Unidos e certos aspectos da cultura latina estavam virando parte do mainstream da vida norte-americana. Mas essa proposta (new American studies), longe de resolver um dos problemas centrais dos Latin Americanists, parecia capaz de agravar o problema. Esse problema pode ser reduzido ao seguinte: qual é o lugar da América Latina num contexto historiográfico preocupado com a provincialização da Europa (ou do Ocidente)? E intimamente ligado com isso é o dilema de reconhecer, até ressaltar, a influência e as várias formas de intervenção dos Estados Unidos na América Latina desde o fim do século XIX, sem atribuir o protagonismo histórico aos Estados Unidos, e colocar a América Latina na posição de objeto da história, nunca de seu sujeito.

Gilbert Joseph, historiador da Yale University, escrevendo nos fins dos anos 90, fez o seguinte comentário sobre os pressupostos problemáticos dos velhos paradigmas da esquerda: "a natureza centrípeta do imperialismo e da dependência (...) arrisca uma conceituação da América Latina somente como sociedades periféricas inteligíveis 
apenas em função dos impactos que eles sofrem das nações do Centro" ${ }^{3}$ (JOSEPH, 1998).

Para muitos Latin Americanists, esta virou a problemática mais urgente justamente porque consolidou uma série de ansiedades, tanto intelectuais como profissionais. Como insistir na importância da América Latina e do Caribe dentro da profissão de historiador e ao mesmo tempo acompanhar a tendência de repensar as fronteiras geográficas do conhecimento e da interpretação histórica? Como captar a atenção de nossos colegas das áreas "preeminentes" e demonstrar o valor de nossas pesquisas para a profissão em geral, e não apenas para os especialistas em história da América Latina? Para citar as palavras de Dipesh Chakrabarty, escritas no fim dos anos 90, "Historiadores do Terceiro Mundo sentem a necessidade de se referir às obras de história europeia; historiadores da Europa não se sentem nem um pouco obrigados a serem recíprocos" (CHAKRABARTY, 2000) (e o mesmo era perfeitamente aplicável aos historiadores dos Estados Unidos).

Claro que essa questão de protagonismo, ou agency, não era inteiramente nova. Talvez o projeto mais urgente da minha turma de Latin Americanists (que, por sinal, eram orientados por uma brasileira exilada, Emília Viotti da Costa) fosse desvendar os limites do "centro" da economia mundial e a consequente capacidade das classes populares, num certo lugar, supostamente periférico, a resistir ao seu domínio. Mas, talvez inevitavelmente, nós mesmos começamos a perceber os limites dessa abordagem, especialmente com relação à questão da modernidade. Porque dentro dessa abordagem, o "centro," o Ocidente, continua representando o "universal" ou o "geral", e a América Latina ou a África ou o Sul da Ásia representavam o "particular". Conseguimos estabelecer a existência de variações locais, mas nossos trabalhos não apresentaram nenhum desafio ou resposta à narrativa de excepcionalismo, que era a coluna vertebral da historiografia inglesa e norte-americana.

Afinal, seria muito difícil mostrar que o Brasil qua Brasil, e muito menos Bolívia qua Bolívia, ou Honduras qua Honduras, tinha algum impacto na história dos Estados Unidos igual à influência norte-americana na América Latina. Enquanto

\footnotetext{
${ }^{3}$ Texto original: "the centripetal nature of imperialism and dependency, which risks conceiving of Latin America solely as 'peripheral societies', intelligible only in terms of the impact that center nations have on them". JOSEPH. Gilbert M. "Close Encounters: Toward a New Cultural History of U.S.-Latin American Relations". In: JOSEPH. Gilbert M.; LEGRAND, Catherine C.; SALVATORE, Ricardo D. (ed.) Close Encounters of Empire. Writing the Cultural History of U.S.-Latin American Relations. Duke University Press, 1998, pp. 13-14.
}

Revista Eletrônica da ANPHLAC, n.14, p. 13-29, jan./jun. 2013. http://revista.anphlac.org.br/index.php/revista 
seguirmos pensando na história das Américas do ponto de vista da nação, fica difícil construir uma historiografia que não privilegie o protagonismo dos Estados Unidos.

É justamente nessa conjuntura que uma abordagem "transnacional” surgiu e ofereceu um novo modo de visualizar as interações e intercâmbios no meio hemisférico ou até global.

Claro que seria difícil, talvez inútil, tentar identificar um único instante quando foi iniciado o "viés transnacional," mas, pelos fins desta palestra, um bom momento fundacional seria o lançamento de dois livros, escritos ou organizados por estudiosos da América Latina, no mesmo ano - 1998 -, que adotaram uma abordagem transnacional.

Um desses livros é o estudo de movimentos sociais transnacionais, Activists beyond borders: advocacy networks in international politics (KECK; SIKKINK, 1998). As autoras, Margaret Keck e Kathryn Sikkink, são cientistas políticas cujos trabalhos anteriores foram dedicados à história política do Brasil e da Argentina. De certa forma, elas estavam procurando uma maneira de valorizar os conhecimentos e questões que estruturaram suas obras anteriores para um público acadêmico norte-americano mais amplo. Examinando movimentos para proteger o meio ambiente e os direitos humanos e historicizando esses movimentos, elas conseguiram desvendar uma longa história de intercâmbio e colaboração entre movimentos sociais anteriormente tidos como limitados a um único contexto nacional. Ainda mais, elas trabalhavam com a diferença entre internacional e transnacional (deixando claro que os dois termos não são sinônimos). $\mathrm{O}$ título da introdução do livro é "Transnational advocacy networks in international politics". A palavra "internacional" aqui significa contatos e interações entre governos (ou seus representantes) ou entre grupos que se identificam, principalmente por sua afiliação nacional. Ao contrário, os participantes nas redes de advocacia, apesar de situados em diferentes contextos nacionais, de propósito privilegiam as causas ou finalidades que eles dividem com suas contrapartidas em outros países.

O outro é o livro Close encounters of empire: writing the cultural history of USLatin American relations, organizado por Gilberto Joseph, Catherine LeGrand e Ricardo Salvatore (JOSEPH; LEGRAND; SALVATORE, 1998) (que são, respectivamente, dos Estados Unidos, do Canadá e da Argentina). Essa coletânea não se identificou, explicitamente, como uma obra de história transnacional, e o capítulo de Seth Fein, "Everyday forms of transnational collaboration: US film propaganda in Cold War Mexico" é o único que traz a palavra "transnacional" no seu título. Mas as preocupações 
e inovações desse tomo combinaram para constituir um guia para renovar a história das relações interamericanas pelo viés transnacional.

Como em qualquer coletânea, há em Close encounters uma variedade de óticas e temas; mesmo assim, acho que podemos perceber uma série de propostas que informam os artigos que compõem o livro. Uma, obviamente, é a necessidade de mudar o nosso enfoque e a nossa atenção da esfera estreitamente política/diplomática/econômica para a esfera cultural, privilegiando as influências e os intercâmbios cotidianos em vez dos momentos espetaculares de intervenção e conflito. Porém, a ideia não é a de mudar da esfera cultural para a esfera política; pelo contrário, o argumento é a impossibilidade de entender os desdobramentos políticos sem uma consideração mais cuidadosa dos intercâmbios culturais, e o papel da cultura nos projetos interamericanos (sejam promovidos pelos estadunidenses, seja pelos latino-americanos ou pelos que não têm um ponto de origem que possamos identificar com clareza).

O segundo pressuposto, intimamente ligado ao primeiro, é que os pesquisadores devem buscar as "zonas de contato" - isto é, os pontos não necessariamente físicos nem geográficos onde os "encontros" internacionais mais intensos transparecem (uma noção derivada do trabalho muito importante da Mary Louise Pratt, Imperial eyes). Esta zona pode ser um lugar físico, como um enclave da United Fruit, na Colômbia, mas também inclui "comunidades" de discurso e conhecimento e o reino do consumismo, espaços que tendem a ser transnacionais.

Um terceiro e também evidente pressuposto é que as relações interamericanas não podem ser pensadas como uma rua de mão única. E não será uma simples questão de incorporar "o lado latino-americano" ou a "resposta" latino-americana, porque isso já implica que existem "dois lados" claros e distintos, um binômio Estados Unidos/América Latina. Ainda mais, esses historiadores, embora bastante preocupados com o peso do "conhecimento" na questão do poder, geralmente rejeitam o modelo de difusão/disseminação que identifica um único ponto de origem de uma ideia (política, científica, tecnológica, econômica) e indica um processo de irradiação desse ponto de origem, de onde ela começa a penetrar novas zonas por vários meios. Em vez desse conceito, que corresponde às noções mais convencionais do "imperialismo cultural", eles preferem o conceito ou a imagem de "circulação cultural" e frisam a constante reformulação de ideias, de propostas e de práticas culturais de um contexto para outro. Então, o exato ponto de origem de certo conceito ou prática (às vezes irrecuperável) é menos importante do que os contextos da sua circulação, implementação e apropriação.

Revista Eletrônica da ANPHLAC, n.14, p. 13-29, jan./jun. 2013. http://revista.anphlac.org.br/index.php/revista 
Assim, por exemplo, a "modernidade" deixa de ser a propriedade exclusiva, com marca registrada, dos Estados Unidos, ou algo "encomendado" ou "imposto" na América Latina. Pelo contrário, certas figuras e grupos em toda parte do Novo Mundo contribuíram com os discursos da modernidade (embora nem todos tivessem a mesma capacidade para materializar certos aspectos do mundo moderno), e essa noção procura extinguir a antiga, mas persistente dicotomia “El Norte Moderno/El Sur Tradicional”.

O último pressuposto, de certa forma uma extensão do anterior, é o seguinte: claro que a história da América Latina pós-colonial é pouco compreensível se não se considerar o papel dos Estados Unidos - o impacto da política, da economia, da cultura norte-americana no desenvolvimento histórico da região. Da mesma maneira, insistem os autores dessa nova tendência, a história dos Estados Unidos seria impossível de se entender sem se considerarem as inúmeras e fortes influências que envolvem a América Latina. Os organizadores de Close encounters levaram a sério a ideia de William Appleman Williams, que identificou "Império" como um "modo de viver" para os norte-americanos.

Quero acentuar que esses trabalhos, considerados pioneiros na área de história transnacional e produtos intelectuais de Latin Americanists, incentivaram um novo rumo nos estudos históricos que logo foi além do campo de América Latina ou até da história das Américas. Do mesmo modo que os "estudos subalternos" surgiram do sul da Ásia, mas viraram uma abordagem mais abrangente, o viés transnacional surgiu dos estudiosos da América Latina, mas logo foi divulgado além das fronteiras da região. $\mathrm{O}$ impulso ao transnacional, no primeiro instante, nasceu dos problemas intelectuais e profissionais dos Latin Americanists na História e nas Ciências Sociais, mas a utilidade dessa abordagem logo atraiu o interesse de pesquisadores em muitas outras áreas.

Agora, uma das explicações para a rápida ascensão do viés transnacional é o declínio de abordagens comparativas. Por muitos anos, uma pesquisa comparando dois ou três casos distintos, geralmente definidos por nacionalidade, foi o modo de interpretação preferido pelo pesquisador que procurava ir além do contexto de uma única nação. Mas, com o viés linguístico e cultural dos anos 80, esse modo de comparação virou alvo de muitas críticas. Ele dependia de uma homogeneização da nação para facilitar a comparação. Os casos comparados tinham que ser "congelados" ou fixos, num certo momento, e as fronteiras entre os casos tinham que ser bem definidas. Nada disso combinava bem com as novas teorias culturais e as noções de história como um processo, e de fronteiras como instáveis e mal definidas. Então acho

Revista Eletrônica da ANPHLAC, n.14, p. 13-29, jan./jun. 2013. http://revista.anphlac.org.br/index.php/revista 
que não podemos dizer que o viés transnacional tem substituído os estudos comparativos - a comparação como método já tinha sofrido uma série de críticas antes do auge do transnacional. Mas, com a divulgação da abordagem transnacional - às vezes associada com o método comparativo -, ficou mais urgente especificar as diferenças entre a abordagem transnacional e a abordagem comparativa, e até insistir que a primeira deve deslocar a segunda. Esse argumento foi articulado com especial insistência pela historiadora Micol Seigel, num ensaio intitulado "Beyond compare" (SEIGEL, 2005) (uma frase que, em inglês, significa "incomparável"). Usando o famoso caso da comparação entre relações raciais no Brasil e nos Estados Unidos, Seigel segue a trajetória desse tema, mostrando as inúmeras zonas de contato, circulação e intercâmbio entre estudiosos e pensadores da questão de raça e identidade racial nos dois lugares, e em até que ponto discursos sobre um ou outro caso viraram um elemento constituinte do conhecimento sobre um ou outro. Portanto, segundo Seigel, tornou-se impossível, e até enganoso, abordar os dois casos como objetos discretos e distintos para os fins da comparação.

Apesar de o artigo ter um enfoque específico - a comparação entre o Brasil e os Estados Unidos -, muitos dos seus leitores têm interpretado o argumento de Seigel (e com razão - acho que essa foi a intenção dela) de um modo mais geral, isto é, considerando que a abordagem transnacional, justamente por mostrar a alta permeabilidade das fronteiras (nacionais, regionais etc.) e a intensa circulação de corpos, ideias e objetos de consumo, questiona a viabilidade da comparação, especialmente entre nações. Ao mesmo tempo, existem aqueles que continuam falando, na mesma frase, de abordagens transnacionais e comparativas - uma frase que aparece em um artigo publicado pelos organizadores do Instituto Tepoztlán, um dos maiores baluartes do viés transnacional. Voltarei a esse assunto mais tarde.

Quero notar também que alguns adeptos do viés transnacional não se colocam na vanguarda de uma tendência totalmente nova, e não tendem a exagerar a novidade da sua abordagem. Pelo contrário, na sua introdução a um número especial da revista Social Text, dedicado ao novo transnacionalismo, Pamela Voekel e Eliot Young (VOEKEL; YOUNG, 2011) insistem que seria mais correto ver o viés transnacional como um movimento de renovação do que de inovação, citando os trabalhos anteriores - especificamente de intelectuais caribenhos, como José Martí, ou da Diáspora Africana, como C.L.R. James e W.E.B. Dubois. E na área de história dos movimentos operários, certos temas, por sua própria natureza (por exemplo, o anarquismo) sempre

Revista Eletrônica da ANPHLAC, n.14, p. 13-29, jan./jun. 2013. http://revista.anphlac.org.br/index.php/revista 
se prestaram a uma abordagem transnacional. Pessoalmente, prefiro essa atitude à postura de muitos intelectuais na época do viés cultural que insistiram na tremenda novidade de seus trabalhos. Ao mesmo tempo, cabe acentuar os aspectos do viés transnacional que são verdadeiramente "novos". O estudo da imigração, por exemplo: parece, à primeira vista, que esse assunto, por sua própria natureza, já introduziu uma abordagem transnacional faz tempo. Mas a velha historiografia da imigração, da Argentina, do Brasil, dos Estados Unidos, foi escrita especificamente para incorporar o imigrante na narrativa nacional. Diferente disso, a ótica transnacional entende a imigração no sentido de um circuito em que existem muitas redes de contato, compromisso, intercâmbio e várias formas de movimento e identidade. Imigração, desse ponto de vista, não é uma história composta simplesmente de um ponto de origem, a transferência geográfica, e a chegada à terra nova. E isso se aplica não apenas às imigrações no mundo de hoje, que são nitidamente multidirecionais, mas também às ondas migratórias do século XIX e início do século XX. Enfim, é sempre importante reconhecer o que nós estamos devendo intelectualmente às gerações anteriores, sem perder de vista as verdadeiras inovações das pesquisas atuais.

Devido ao enorme impacto do viés transnacional desde o fim dos anos 90, seria impossível mencionar todos os trabalhos relevantes publicados ou ainda inéditos que envolvem a América Latina (que, na minha opinião, continua sendo a área mais produtiva para os estudos transnacionais). Então, vou apenas salientar alguns trabalhos que representam as várias tendências florescendo dentro da penumbra do viés transnacional.

Sem dúvida, o maior vertente de estudos transnacionais continua tratando das relações hemisféricas, com uma ênfase nos intercâmbios e colaborações dos cientistas sociais e outros experts que influenciaram as políticas governamentais, mas que circularam fora do contexto do oficialismo. Por exemplo, Karin Rosemblatt, Latin Americanist na University of Maryland, está completando um estudo dos antropólogos e sociólogos no México e nos Estados Unidos no pós-guerra que trabalhavam com os temas de cultura, pobreza e família, mostrando a centralidade da Antropologia mexicana na obra do Oscar Lewis e outros, e seu papel na formação da política relativa à pobreza, especialmente dentro da comunidade negra, nos Estados Unidos. O estudo de Rosemblatt não é somente um retrato desse intercâmbio e dessa circulação de ideias, dados e discursos, mas também - e igualmente interessante - do processo pelo qual os 
experts norte-americanos apagaram a contribuição das pesquisas mexicanas, assim reforçando suas noções de excepcionalismo e pioneirismo norte-americano.

Há vários estudos, ainda inéditos, nessa linha. Ultimamente, li um capítulo de uma tese de doutorado sobre os problemas de habitação urbana nas décadas de 50 e 60 , nos Estados Unidos e na Colômbia, que trata de várias questões que também aparecem no trabalho de Rosemblatt. A autora segue a carreira de vários engenheiros, arquitetos e planejadores urbanos que circulavam entre os Estados Unidos e a Colômbia, particularmente na época da Aliança para o Progresso, e o trabalho desvenda vários instantes de experiências com conjuntos habitacionais para pessoas de baixa e média renda em Bogotá e Medellín que foram depois incorporadas em projetos norteamericanos. Mas é interessante notar que, nesse caso, a autora, Amy Offner, entrou no projeto do lado norte-americano - ela é orientanda do eminente historiador norteamericano Eric Foner e acabou de ser contratada pela University of Pennsylvania para uma vaga na área da United States and the World.

A identidade profissional de Rosemblatt é Latin Americanist, e a de Offner é Americanist; certamente, há uma série de diferenças nos seus perfis intelectuais que correspondem a essas identidades distintas. Mas, lendo os trabalhos delas, essa diferença não se manifesta claramente. As duas trabalham com fontes em inglês e espanhol, as duas consultam arquivos e fazem entrevistas tanto nos Estados Unidos como na América Latina. E as duas estão construindo uma história que transborda os limites de um ou outro país.

Outra área dinâmica de pesquisa transnacional é mais preocupada com a esfera da cultura, que nesse caso significa cinema, música, literatura, artes plásticas, comida e políticas culturais. Um dos trabalhos mais divulgados dessa vertente é o livro de Micol Seigel, Uneven encounters: making race and nation in Brazil and the United States (SEIGEL, 2009), que se posiciona explicitamente na categoria de história transnacional; outro é o artigo de Lauren Derby, no volume Close encounters (DERBY, 1998), sobre o vaivém dos dominicanos entre o Caribe e Nova York e seu impacto na identidade nacional. Tanto Seigel como Derby insistem na relação entre o transnacional e o nacional na esfera de intercâmbio cultural e representações culturais. Longe de ver o transnacional apagando o nacional, os dois mostram como ligações além da nação servem para fortalecer a posição de certo grupo ou tendência dentro da nação. No seu artigo "Gringo chicken with worms" (Frango gringo com vermes), Derby usa como seu ponto de partida um "pânico" na República Dominicana em 1992, provocado por 
acusações de contaminação do frango produzido com técnicas industriais por uma empresa norte-americana. Segundo os boatos, o frango estava causando esterilidade entre os homens dominicanos, entre outros danos; portanto, o "boicote" ao "frango gringo" levou também a uma revalorização da galinha criolla. Neste "encontro desigual" (para usar a frase de Micol Seigel), a comida virou uma medida para repensar a natureza da identidade.

Claro que esse pânico não se explica por uma simples onda de xenofobia. Ele ocorreu exatamente numa época em que quase metade da população dominicana estava morando fora da ilha e quando a nação dominicana ficou cada vez menos equivalente a um definido trecho de terra. Nem mesmo os dominicanos que ficaram no Caribe podiam fugir da transnacionalização do povo dominicano. Foi nesse contexto de desestabilização radical da noção de "lar" e de nação que a comida assumiu um significativo essencial, um símbolo do dominicano autêntico.

Uma terceira vertente no quadro transnacional consiste em estudos que modificam nossa imagem de certas formações econômicas. À primeira vista, os estudos desse tipo podem parecer nada especialmente novo - o papel do capital estrangeiro, o surgimento de um mercado global -, são temas bem estabelecidos. Mais uma vez, a contribuição nova é mostrar que as divisões entre "nacional" e "estrangeiro" não são sempre tão claras e bem definidas como imaginamos. Há, por exemplo, alguns trabalhos que procuram revisar nossa noção da economia de "enclave". Longe de ser espaços isolados, no sentido econômico, político ou social, Catherine LeGrand insiste que as aldeias da United Fruit Company, na Colômbia e no Caribe, eram espaços altamente cosmopolitas e que o radicalismo político desses locais não era por causa da concentração e intensificação de uma cultura de resistência, mas, pelo contrário, devido a muitas influências transnacionais que instigaram uma variedade de políticas oposicionistas (LEGRAND, 1998). Seguindo a mesma linha, em uma tese de doutorado recentemente defendida na NYU, Frances Sullivan chama de "cosmopolitismo popular" a cultura das company towns no norte do Oriente, em Cuba. Essas aldeias, numa zona de enormes plantações de cana e engenhos gigantescos dominados por imensas empresas norte-americanas, foram consideradas como exemplos clássicos do enclave. Mas Sullivan desvenda o constante influxo de novas correntes migratórias e de novas influências culturais e ideológicas. Entre elas, Marcus Garvey e seu United Negro Improvement Association tinham um grande impacto entre os afrodescendentes, e sua influência não era restrita aos caribenhos anglófonos. Clubes, desfiles, comícios, 
boletins deixaram evidências da importância de Garveyismo nessa região. Várias tendências da esquerda, inclusive o Partido Comunista Cubano, tinham presença política e cultural nessas company towns, e esses locais formaram o baluarte do antifascismo, com muito clubes para dar apoio aos republicanos durante a Guerra Civil na Espanha. Mais ainda: centenas de homens desses “enclaves” viajaram à Espanha para se integrar nas brigadas internacionais. A velha imagem do enclave era a de um local onde uma sociedade "tradicional" de repente se achou subordinada à modernização brutal do capital estrangeiro. Nesses novos estudos, a brutalidade das empresas e suas tentativas para impor o seu domínio na região ainda ocupam um lugar central, mas não são mais os donos exclusivos da modernidade.

É inevitável que esta breve relação de estudos transnacionais de autoria norteamericana seja muito parcial, e a lista de artigos e livros que seguem essa abordagem só vai crescer nos próximos anos. Mais uma vez, o viés transnacional, neste momento histórico, tem um forte apelo para os Latin Americanists. Diferente do conceito da globalização, um conceito que supõe o declínio da nação e que é, do meu ponto de vista, profundamente comprometido com o neoliberalismo, os estudos transnacionais geralmente reconhecem a persistência da nação como uma esfera principal da política, da economia e da cultura. De um lado, isso permite uma maior atenção aos processos, às redes e aos fenômenos de todo tipo que atravessam as fronteiras da nação sem implicar a homogeneização; de outro, o transnacional nos permite ir além da identificação de particularidades ou especificidades num contexto nacional. Para acentuar este último aspecto do viés transnacional, quero falar brevemente do livro The making of the middle class: toward a transnational history (WEINSTEIN; LOPEZ, 2012), lançado em janeiro de 2012 e organizado por mim e meu colega e ex-aluno Ricardo López. Essa coletânea não é exclusivamente dedicada à história da América Latina, nem das Américas, mas seis dos dezesseis capítulos tratam diretamente da classe média em países latino-americanos.

Uma rápida genealogia da historiografia da classe média ajuda a acentuar o que nós consideramos "nova" na nova história transnacional. No auge da nova história social (anos 70), havia pouco interesse na classe média, e o consenso entre os estudiosos de países além da América do Norte e da Europa Ocidental foi que, nessas regiões, a classe média ou era quase inexistente, ou não cumpria seu suposto papel histórico. Nos anos 90, depois do viés cultural, uma série de estudos apareceu, especialmente no contexto da América Latina (Brian Owensby, Intimate ironies (OWENSBY, 1999), 
sobre o Brasil; David Parker, The idea of the middle class (PARKER, 1998), sobre o Peru; e Patrick Barr-Melej, Reforming Chile (BARR-MELEJ, 2001)) e prestou mais atenção à construção de uma cultura, política e sensibilidade da classe média. Esses autores demonstraram a existência e importância da classe média, mas, ao mesmo tempo, insistiram que tal classe, nesses locais, não fosse uma exata reprodução do paradigma da classe média associada aos Estados Unidos ou à Grã-Bretanha. É inegável que essas variações nas culturas e práticas da classe média existem, e seria absurdo imaginar que qualquer formação social iria se reproduzir de idêntica maneira em toda parte do mundo. Mas o defeito ou limitação dessa historiografia é o seguinte: esses autores ainda estão trabalhando com uma noção normativa ou paradigmática da classe média que começa na Inglaterra e nos Estados Unidos e de lá vai se espalhando para os países periféricos (e talvez menos modernos), onde a cultura e identidade da classe média sofrem certas alterações que refletem as particularidades do lugar (por exemplo, Parker, falando de Peru, mostra que o empregado de colarinho branco é a figura típica da classe média e, por isso, se aproxima mais da mentalidade do operário, enquanto Owensby enfatiza a persistência da cultura de patronagem e clientela junto com o discurso de mérito no Brasil). Qual é o problema com essa formulação? Primeiro, Owensby toma o contexto nacional como o quadro adequado para entender as qualidades particulares da classe média brasileira (usando o Rio e São Paulo como representantes do Brasil da classe média). Mas acho que seria errado supor que a história da classe média no Rio e em São Paulo seja igual simplesmente por serem duas cidades dentro das fronteiras do mesmo país (e diria o mesmo de Lima e Arequipa, no Peru). Se a preocupação é demonstrar as particularidades, talvez o contexto subnacional - isto é, regional - seja mais adequado do que a nação.

O outro defeito - e isso eu considero mais grave - é que esses estudos, longe de questionar a narrativa da modernidade como invenção europeia/norte-americana, reforça essa grande narrativa porque, segundo eles, a classe média, em locais como Chile, Peru e Brasil, é apenas uma variação, com traços ou qualidades vestigiais menos modernas.

Então, qual é a proposta da coletânea The making of the middle class? Primeiro, o volume procura contestar a noção da classe média paradigmática. Simon Gunn debate a ideia da classe média padrão na Inglaterra, acentuando a contínua distância entre a sua imagem e seu papel na sociedade inglesa (por exemplo, havia frequentes críticas à sua falta de autonomia política e à sua tendência de macaquear a classe aristocrática). Carol

Revista Eletrônica da ANPHLAC, n.14, p. 13-29, jan./jun. 2013. http://revista.anphlac.org.br/index.php/revista 
Harrison mostra que o catolicismo foi essencial na formação da cultura da classe média na França - e, por extensão, mostra que a nossa ideia da classe média francesa como um baluarte do secularismo é um mito. Marina Moskowitz e Daniel Walkowitz examinam as várias culturas da classe média nos Estados Unidos e as variações regionais e políticas (por exemplo, no meio oeste, um aspecto fundamental de ser da classe média no início do século XX era um lar sem serventes. Mas no sul do país seria impossível ter pretensões de pertencer à classe média sem serventes).

A outra face dessa moeda é o argumento do Sanjay Joshi, historiador da Índia colonial, que retrata o que ele chama da fractured modernity (modernidade fragmentada) da classe média em Lucknow na época do domínio britânico. É essa experiência de modernidade, diz Joshi, que é mais paradigmática, ou pelo menos mais típica das classes médias em todas as partes do mundo.

Então, os capítulos que tratam de casos latino-americanos estão situados, agora, não como variações implicitamente defeituosas de um ideal mais plenamente moderno, mas como instâncias de engajamento com um repertório de imagens, normas e práticas associadas à ideia de classe média. Mais uma vez, o viés transnacional, com sua ênfase na circulação, em vez da difusão, permite uma visão da classe média que dispensa o tipo ideal e complica qualquer tentativa de "medir" a modernidade de um caso em particular, ou de distinguir nitidamente o particular e o geral.

Bom, até agora estou falando principalmente das muitas "vantagens" do viés transnacional, e falando de modo geral acredito que esta abordagem tem aberto caminhos novos e produtivos para os historiadores da América Latina. Mas não posso deixar de falar dos perigos ou dificuldades que o viés transnacional traz no seu bojo, especialmente para o campo da história da América Latina.

Ao longo das últimas duas ou três décadas, acho que podemos notar uma maior integração entre historiadores da América Latina radicados nos países que são objeto dos seus estudos e os Latin Americanists. Geralmente isso transparece num contexto nacional especifico. Claro que há exceções - por exemplo, o tema da escravidão e emancipação tem gerado uma comunidade de pesquisadores que me parece realmente transnacional. Mas, do modo geral, um Latin Americanist vira especialista num país especifico - Brasil, México, Chile, Peru - e acumula uma profunda familiaridade com a historiografia, política e cultura daquele país e com suas instituições universitárias e de pesquisa. E cria laços de amizade e colaboração com os colegas das principais instituições e, na melhor das hipóteses, forma certo compromisso com a comunidade 
acadêmica. Vale a pena pensar se uma proliferação de estudos transnacionais, estudos que não privilegiam a historiografia nacional, pode significar uma diminuição da intensidade desses conhecimentos e desses laços de intercâmbio e amizade. E a outra face dessa moeda é a questão da inclusão e exclusão da onda transnacional. Obviamente, um projeto de pesquisa que envolve arquivos e acervos em vários países inevitavelmente exige acesso a várias bolsas de pesquisa e outros meios de apoio ao pesquisador. É só com grande esforço que um historiador nos Estados Unidos (ou no Brasil) consegue a verba de que necessita para tal pesquisa; então imagine um historiador radicado num país como o Peru, a Bolívia, o Panamá, o Equador ou a Nicarágua, que não dispõe de muitos recursos, na melhor das hipóteses. Seria lamentável que os trabalhos desses historiadores ficassem menos prestigiados por serem voltados principalmente a questões nacionais.

Desigualdades de prestígio e de recursos são elementos que merecem consideração também no contexto da academia norte-americana. Como indiquei antes, um dos efeitos colaterais do viés transnacional é um passo na direção de estudos hemisféricos e o chamado new American studies. Mais uma vez, falando de modo geral, simpatizo com essa tendência, e acredito que os historiadores que trabalham nessa linha levam muito mais a sério a necessidade de dominar determinados idiomas e pesquisar em arquivos fora dos Estados Unidos. A própria categoria de "Estados Unidos e o Mundo" (em vez de "história diplomática" ou de relações exteriores) já indica esse novo rumo. E em geral dou apoio à tendência de desestabilizar as fronteiras historiográficas. Como observa Gilbert Joseph, “essa visão menos definida de fronteiras, de quem ou de qual seja autóctone e qual seja alheio, interno ou externo, caracteriza a teoria crítica atual numa variedade de disciplinas (...)" ${ }^{4}$ (JOSEPH, 1998).

E a expectativa é de que essa tendência vá aumentando o peso intelectual da América Latina na academia norte-americana. Mas, devido ao enorme espaço que a história dos Estados Unidos ocupa nas universidades norte-americanas, precisamos (eu e meus colegas lá) levar em conta outras possibilidades, menos agradáveis para os Latin Americanists. Uma delas seria certa pressão no meio acadêmico para estudos transnacionais que incorporam grupos, indivíduos ou práticas ligadas em algum

\footnotetext{
${ }^{4}$ Texto original: "This blurring of boundaries, of who or what is 'local' and 'foreign', 'inside' or 'outside', characterizes contemporary critical theory across a variety of fields". JOSEPH. Gilbert M. "Close Encounters: Toward a New Cultural History of U.S.-Latin American Relations". In: JOSEPH. Gilbert M.; LEGRAND, Catherine C.; SALVATORE, Ricardo D. (ed.) Close Encounters of Empire. Writing the Cultural History of U.S.-Latin American Relations. Duke University Press, 1998, p. 16.
}

Revista Eletrônica da ANPHLAC, n.14, p. 13-29, jan./jun. 2013. http://revista.anphlac.org.br/index.php/revista 
momento aos Estados Unidos, de preferência a estudos que envolvem principalmente, ou exclusivamente, latino-americanos. Também o desequilíbrio entre os arquivos e bibliotecas norte-americanos, de um lado, e os arquivos latino-americanos, de outro, pode reforçar a tendência de privilegiar a abordagem hemisférica.

Em princípio, o viés transnacional não deve ter esse desfecho, muito pelo contrário. Mas vale a pena lembrar a observação de Edward Thompson, que, no livro Senhores e caçadores, lamentou que não houvesse maneira de se armar contra o leitor desatento. E é pior ainda quando existem condições que conspiram para reforçar a falta de atenção.

Enfim, temos que tomar cuidado para não jogar fora o bebê com a água do banho. O tão criticado conceito de area studies, apesar de suas raízes na Guerra Fria, tem evoluído na academia norte-americana e conseguido valorizar o estudo da América Latina e do Caribe como uma área de pesquisa histórica que é legítima em si mesma em primeira instância, não importa o número de pessoas de descendência latina nos Estados Unidos, nem os interesses políticos do governo norte-americano. Levando isso em conta, acho desaconselhável abrir mão da ideia de area studies simplesmente por desgostar-se do seu ponto de origem.

Ao mesmo tempo, nenhum desses "perigos" deve ser fatal para o viés transnacional. Minha intenção aqui é registrar algumas inquietações; não pretendo, de jeito nenhum, montar um argumento contra a história transnacional. No final das contas, a história transnacional é mais bem entendida como uma abordagem que complica, e não desloca a história nacional. Ainda mais: a história transnacional, parecida com gênero, é uma abordagem que pode ser aplicada a um grande leque de assuntos. Claro que a idoneidade do viés transnacional é mais evidente para certos assuntos do que outros. Porém, é difícil imaginar um tema histórico nos últimos dois séculos, começando com a micro-história local, que não envolva algum elemento do transnacional. Finalmente, retomando o tema da abordagem comparativa, não acho que a ascensão do viés transnacional signifique a morte da comparação. Pode ser que seja o fim daquela comparação "científica" e positivista - o que não me parece nada lamentável. Mas acho que ele oferece uma nova maneira de fazer comparação. Vou terminar com um belo exemplo disso: umas três semanas atrás, participei da banca de um aluno da University of Maryland, que estava defendendo uma tese de doutorado sobre a política de habitação na América Latina durante as primeiras décadas da Guerra Fria. Na tese, ele examinou a formação de uma comunidade hemisférica de experts nos

Revista Eletrônica da ANPHLAC, n.14, p. 13-29, jan./jun. 2013. http://revista.anphlac.org.br/index.php/revista 
anos 50 e 60 que identificaram a moradia como um aspecto essencial do processo de modernização e criaram certa visão de pobreza urbana na América Latina. Mas, dentro desse quadro, ele examinou especificamente os vários projetos habitacionais iniciados no Rio e em Buenos Aires nessa época. A banca toda achou a tese muito boa e elogiou o novo doutor, mas chegou um momento em que um professor insistiu que a tese foi um trabalho transnacional e que a ênfase no eventual livro deve ser essa (e, de fato, o autor mostra que, apesar da existência de condições altamente distintas no Rio e em Buenos Aires, a política transnacional habitacional sofreu poucas alterações entre um e outro contexto), enquanto um segundo professor insistiu que o interessante foram os pontos de contraste entre os dois casos e queria que o autor frisasse mais a comparação. Então sobrou para mim o papel de Cachinhos Dourados e ofereci o seguinte conselho: o autor não precisa optar exclusivamente nem para o transnacional, nem para a comparação. Na verdade, para mim o trabalho dele demonstra que, no instante em que saímos da esfera do intercâmbio intelectual, é muito difícil, talvez impossível, não recorrer à comparação. Elaborada num quadro transnacional, evitamos a tendência de reificar as diferenças; citando Gil Joseph mais uma vez, é preciso lembrar que "as ideias, instituições e outras formas culturais e econômicas são, na maioria das vezes, o sedimento bagunçado de intercâmbios anteriores" 5 (JOSEPH, 1998). Então, pela ótica dele, não existe nenhuma possibilidade de uma clara separação entre dois casos, o que, para Joseph, torna a comparação inútil. Mas a comparação não depende de uma separação total das entidades sendo comparadas. Não é apenas uma questão de contraste; aliás, nós geralmente pensamos em comparar entidades que consideramos “comensuráveis" - por isso, a famosa não comparação entre maçãs e laranjas. Desse ponto de vista, o viés transnacional, longe de expulsar a comparação, permite uma renovada abordagem comparativa mais adequada às preocupações do historiador.

Artigo recebido em julho de 2012.

\footnotetext{
${ }^{5}$ Texto original: "ideas, institutions, and other cultural and economic forms are more often the messy sediments of previous exchanges". JOSEPH. Gilbert M. "Close Encounters: Toward a New Cultural History of U.S.-Latin American Relations". In: JOSEPH. Gilbert M.; LEGRAND, Catherine C.; SALVATORE, Ricardo D. (ed.) Close Encounters of Empire. Writing the Cultural History of U.S.-Latin American Relations. Duke University Press, 1998, p. 16.
}

Revista Eletrônica da ANPHLAC, n.14, p. 13-29, jan./jun. 2013. http://revista.anphlac.org.br/index.php/revista 


\section{Referências Bibliográficas}

ANDERSON, Benedict R. Comunidades imaginadas: reflexões sobre a origem e a difusão do nacionalismo. São Paulo: Companhia das Letras, 2008. (Original: Imagined communities: reflections on the origin and spread of nationalism, 1983).

BARR-MELEJ, Patrick M. Reforming Chile: Cultural Politics, Nationalism, and the Rise of the Middle Class. The University of North Carolina Press, 2001.

CHAKRABARTY, Dipesh. Provincializing Europe. Postcolonial Thought and Historical Difference. Princeton University Press, 2000.

DERBY, Lauren. Gringo Chickens with Worms: Food and Nationalism in the Dominican Republic. In: JOSEPH. Gilbert M.; LEGRAND, Catherine C.; SALVATORE, Ricardo D. (ed.) Close Encounters of Empire. Writing the Cultural History of U.S.-Latin American Relations. Duke University Press, 1998.

JOSEPH. Gilbert M. Close Encounters: Toward a New Cultural History of U.S.-Latin American Relations. In: JOSEPH. Gilbert M.; LEGRAND, Catherine C.; SALVATORE, Ricardo D. (ed.) Close Encounters of Empire. Writing the Cultural History of U.S.-Latin American Relations. Duke University Press, 1998, p. 16.

JOSEPH. Gilbert M.; LEGRAND, Catherine C.; SALVATORE, Ricardo D. (ed.) Close Encounters of Empire. Writing the Cultural History of U.S.-Latin American Relations. Duke University Press, 1998.

KECK, Margaret E.; SIKKINK, Kathryn. Activists Beyond Borders: Advocacy Networks in International Politics. Cornell University Press, 1998.

LEGRAND, Catherine C. Living in Macondo: Economy and Culture in a United Fruit Company Banana Enclave in Colombia. In: JOSEPH. Gilbert M.; LEGRAND, 
Catherine C.; SALVATORE, Ricardo D. (ed.) Close Encounters of Empire. Writing the Cultural History of U.S.-Latin American Relations. Duke University Press, 1998.

OWENSBY, Brian P. Intimate Ironies. Modernity and the Making of Middle-Class Lives in Brazil. Stanford University Press, 1999.

PARKER, David S. The Idea of the Middle Class: White-Collar Workers and Peruvian Society, 1900-1950. Penn State University Press, 1998.

SEIGEL, Micol. Beyond Compare: Comparative Method after the Transnational Turn. Radical History Review, Issue 91， 2005, pp. 62-90.

. Uneven Encounters: Making Race and Nation in Brazil and the United States. Duke University Press, 2009.

VOEKEL, Pamela; YOUNG, Elliott. The Tepoztlán Institute for the Transnational History of the Americas. Social Text, issue 92, 2011.

WEINSTEIN, Barbara; LÓPEZ, Ricardo (ed.). The Making of the Middle Class: Toward a Transnational History. Duke University Press, 2012. 